\title{
Artistas cearenses e circulação da música popular
}

\section{Mariana Barreto ${ }^{1}$ Gabriella André 2}

Resumo

Este artigo traz os mais recentes resultados de nossa pesquisa "Artistas cearenses e circulação da cultura popular", cujo o objetivo primordial é estudar as carreiras dos artistas populares a fim de testar a hipótese da existência ou não de recorrências na forma como se estruturam. Tomamos como objeto empírico a carreira dos músicos integrantes de quatro grupos de "vocalistas" formados no Ceará entre os anos de 1940 e 1950: Quatro Ases e Um Coringa, Vocalistas Tropicais, Trio Nagô e Trio Guarani, todos representativos de um tipo de música popular que assumiu diferentes significados ao longo da formação de nossa identidade nacional. Para esta interpretação inicial, priorizamos o estudo das trajetórias destes músicos e de seus grupos observando de que modo o Ceará se insere na questão nacional e realiza sua relação com o popular. Manuseamos os dados empíricos coligidos até o momento sobre os Quatro Ases e Um Coringa e os Vocalistas Tropicais, dois dos mais expressivos conjuntos de intérpretes e instrumentistas da tradição musical popular brasileira.

Palavras-Chave: música popular, tradições musicais e artistas cearenses.

\section{Artists from Ceará and the circulation of popular music}

\section{Abstract}

This article presents the most recent results from our research "Artists from Ceará and Popular Culture Circulation". This project's main goal is to study the careers of popular artists in order to test the hypothesis of the existence or not of a pattern that somehow defines their structure. We took as an empirical object the career of four lead singers from music groups forged during the 1940s and 1950s in Ceará: Quatro Ases e Um Coringa, Vocalistas Tropicais, Trio Nagô and Trio Guarani, all representative of a type of popular music which undertook different meanings throughout the development of our national identity. For this introductory interpretation, we set as a priority to study the trajectories of these musicians and their groups, observing how Ceará inserts itself in the national scenario and solidifies its relation to what is "popular". We access and treat the empirical data gathered so far on Quatro Ases e Um Coringa and the Vocalistas Tropicais, two of the most expressive groups of performers and instrumentalists on the Brazilian popular music tradition.

Keywords: popular music, musical traditions and artists from Ceará.

1 Mariana Barreto é mestre e doutora em sociologia pela Universidade Estadual de Campinas - UNICAMP, professora adjunta III do Departamento de Ciências Sociais da Universidade Federal do Ceará - UFC. mariana.barreto@pq.cnpq.br. 2 Gabriella André é graduanda em ciências sociais pelo mesmo departamento e bolsista de iniciação científica, para o ano de 2018 - 2019, no projeto “Artistas cearenses e circulação da cultura popular”. gabriellaandreufc@gmail.com 


\section{Introdução}

Este artigo, embora trazendo reflexões ainda incipientes, segue uma ampla hipótese, isto é, a de que coisas que estão muito longe no espaço geográfico podem estar muito próximas no espaço pertinente a um campo; ou, por outras palavras, a ideia de que os fenômenos de nacionalização das culturassefazem a partir dos eventos de circulação, trocas e transferências, muitas vezes ocultados pelos processos de criação das identidades nacionais. De modo semelhante, o texto segue outra hipótese mais restrita, a existência ou não de uma correspondência entre as formas como se desenvolveram as trajetórias artísticas dos artistas populares, oriundos das classes populares, e a reprodução das desigualdades sociais brasileira ${ }^{3}$. Para testá-las, tomamos como objeto de análise a trajetória artística de quatro grupos de vocalistas e instrumentistas musicais formados no Ceará, entre os anos de 1940 e 1950, que se destacaram nos cenários nacional e internacional da produção musical: Quatro Ases e um Coringa, Vocalistas Tropicais, Trio Nagô e Trio Guarani.

Nosso problema maior de pesquisa está centrado no fato de que autonomizados durante o processo de construção da identidade nacional, os percursos artísticos destes músicos os inseriu num espaço internacional de competição, a partir de uma base cultural (nacional) e territorial bem estabelecidas, que foi parte importante na formação do capital simbólico acumulado pela música popular brasileira ao longo dos anos. Regionalistas vencedores na concorrência nacional, quase todos os integrantes têm a mesma origem social e formações musicais. Compõem e interpretam sambas, sambas-canção, marchas, batuques, baiões e outros gêneros representativos da tradição da música brasileira naquele período. Os itinerários destes músicos seguem os de outros regionalistas produzidos pela nacionalização acelerada da época: são estudantes dos liceus, integram bandas militares, autodidatas, não profissionalizados, migraram para o centro cultural do país, Rio de Janeiro, para seguir seus estudos, frequentar as universidades, ou mesmo tentar carreira artística nas estações de rádio.

Em nosso projeto "Artistas Cearenses e circulação da cultura popular" temos como objetivos entender como estes grupos são absorvidos pelo campo da produção musical, naquelemomentoem queacidadedoRiodeJaneiro representa o lugar do monopólio de consagração mais legítimo; como o regionalismo destes grupos se integra à cultura nacional; compreender como se deu o acesso ao reconhecimento, as maneiras como se distribuíram nas hierarquias de prestígio existentes; conhecer quais instâncias ofereceram a estes artistas condições materiais de criação, ou seja, quais instâncias de acesso ao reconhecimento dispunha o Ceará, em 19401950, capazes de jogar um papel essencial na emergência e/ou consolidação de suas carreiras artísticas, quais os lugares, na capital cearense, mas também no Rio de Janeiro, definiram o valor artístico e econômico destes artistas. E de modo equivalente, compreender como contribuíram para a exportação da notoriedade da música popular brasileira, passage obligé para a distinção e manutenção da excelência dos grupos musicais. Em última instância, interessa-nos observar o que estes grupos revelam da constituição do campo de produção da música popular brasileira, o que denotam sobre a formação da identidade nacional na esfera musical em termos de uma territorialidade artística nacional, cuja construção do valor e formas de excelência não se fez nos limites de um quadro nacional.

Para este artigo, no entanto, nos dedicaremos à interpretação inicial dos dados empíricos coligidos até o momento sobre as trajetórias do Quatro Ases e Um Coringa e Vocalistas Tropicais, tomando-os como objetos heurísticos capazes 
de fazer ver como o Ceará se insere na questão nacional e realiza sua relação com o popular. A incipiência do material empírico disponível não nos permitiria avançar nas análises dos dois mais expressivos conjuntos de intérpretes e instrumentistas da tradição musical popular brasileira.

Quatro Ases e Um Coringa e o privilégio do lugar de origem

Quatro Ases e Um Coringa foi, em alguma medida, produto de algumas reconfigurações do chamado Bando Cearense, originalmente formado em 1940 por universitários cearenses, vivendo no Rio de Janeiro (AZEVEDO, 2004). O grupo foi renomeado como Quatro Ases e Um Coringa pelo jornalista Demócrito Rocha, numa referência ao fato de ser composto por cinco instrumentistas, dentre eles um pandeirista cujo apelido era Melé, variação popular, no nordeste, do nome da carta curinga, no jogo de cartas. De volta ao Rio de Janeiro, os músicos adotaram definitivamente o novo nome do quinteto. Quatro Ases e Um Coringa gravou músicas dos mais expressivos compositores cearenses, dentre eles Paurillo Barroso e Lauro Maia, lançou novos letristas, novos intérpretes, acompanhou e foi acompanhado por estrelas do rádio como Marlene e Orlando Silva. Gravou mais de uma centena de discos, boa parte deles pela Odeon, gravadora referência na produção e distribuição de música popular.

\section{Figura 1- Quatro Ases e Um Coringa.}

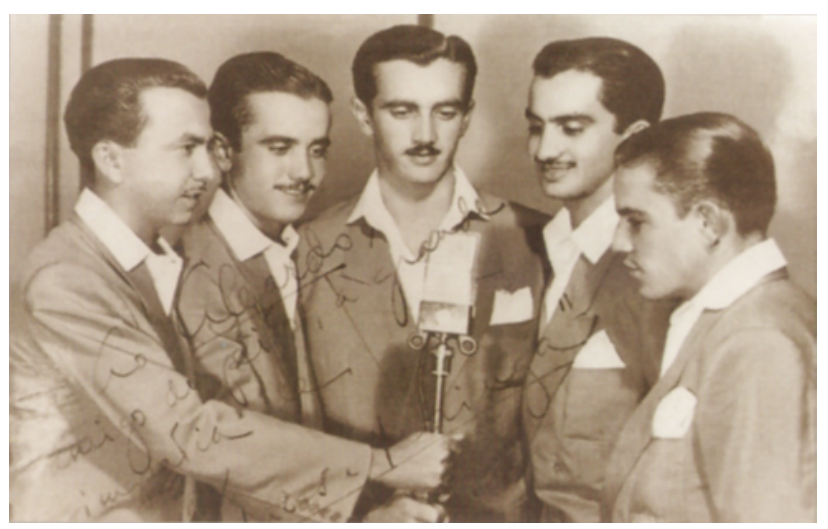

FONTE: AZEVEDO, Miguel A. de. Música popular no enfoque. CHAVES, Gilmar; VELOSO, Patricia. e CAPELO, Peregrina. (Orgs.). Ah, Fortaleza. 2a Edição. Fortaleza: Terra da Luz, 2009. p. 151.

Durante os anos de 1940 o grupo formado pelos cearenses: Evenor Pontes de Medeiros, José dePontes Medeiros, Permínio Pontes de Medeiros, André Batista Vieira e Esdras Falcão Guimarães. Sua formação original parece ter sofrido apenas duas grandes substituições: em 1952, quando Jorginho do Pandeiro substituiu André Vieira e, posteriormente, quando Miltinho substituiu Nilo, que entrara para executar as funções de Jorginho do Pandeiro (CRAVO ALBIN, 2018). Esta estabilidade contribuiu para transformá-los num dos mais importantes e longevos grupos a ocupar posições privilegiadas na hierarquização das reputações e notoriedades de artistas e obras na produção da música popular brasileira.

Estabelecidos desde o início na cidade do Rio de Janeiro, seguiram o trajeto semelhante ao de outros artistas que se consagraram em grupos vocais e instrumentais, enfrentaram um processo conduzido por uma sucessão de etapas mais ou menos longas e complexas, segundo as lógicas de reconhecimento que prevaleceram no campo artístico naquele momento, isto é, trabalharam como crooners, solistas, apresentando-se nos programas das emissoras de rádio, até serem contratados para o cast das mesmas, gravando discos, fazendo shows e turnês dentro do país em boates, cassinos e fora, em excursões pela Europa e demais países da América Latina, além das composições de trilhas sonoras para filmes e atuações nos mesmos.

Os gêneros musicais privilegiados acompanhavam os padrões hegemônicos que iam se estabelecendo ao longo da história da música popular brasileira, ou seja, ao longo dos anos 40 gravaram, em sua maioria, sambas, frevos e marchas; com o advento da nova década intensificaram as gravações de xotes, baiões e rancheiras, acompanhando as metamorfoses dos significados e sentidos do popular na música 
brasileira $^{4}$. A consagração do grupo pode ainda ser evidenciada pelas vezes em que foram tema da Revista do Rádio, um dos periódicos mais emblemáticos do reconhecimento da notoriedade de artistas e intermediários que trabalhavam no campo da produção musical.

Figura 2 - Capa da Revista do Rádio - Quatro Ases e Um Coringa.

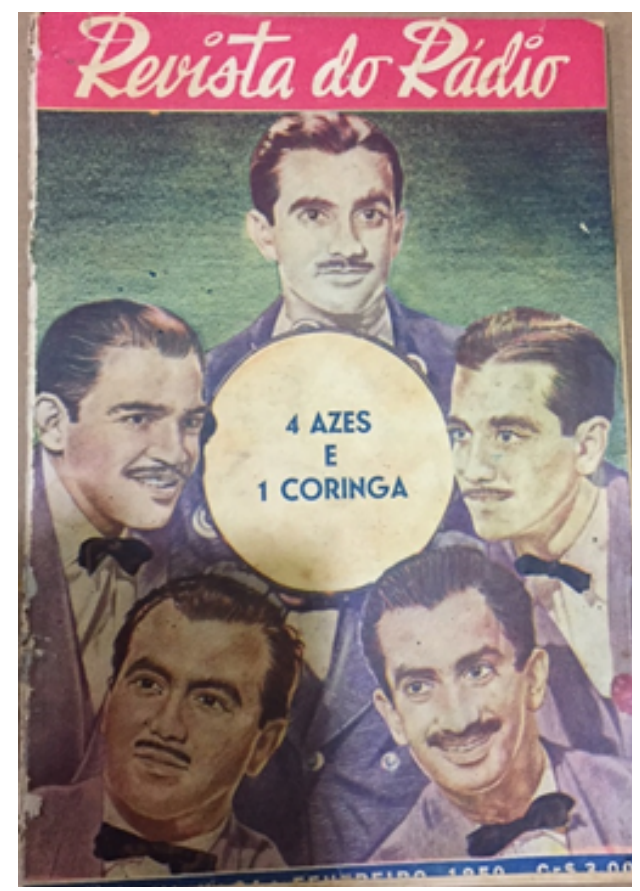

FONTE: Revista do Rádio, Ano III, No 24, Fevereiro de 1950. Acervo Nirez.

Em fevereiro de 1950, a publicação mensal, com tiragem de 50.000 exemplares, dedica a capa de seu número 24 aos Quatro Ases e um Coringa justificando

Em nosso número de dezembro último contamos a história dos "Quatro Azes e Um Coringa", os cinco cearenses que formaram um dos melhores conjuntos do rádio brasileiro. Hoje estamos dando nesta edição a mais recente fotografia dêsse quinteto numa concepção artística do desenhista Adão Pinho, que pertence com exclusividade à Rádio Nacional. Como acontece todos os anos os “Quatro Azes e Um Coringa” deverão aparecer com bastante destaque no carnaval que chega, pois as músicas que gravaram vêm tendo ampla aceitação, agradando bastante (Revista do Rádio, 1950, p. 5).

A Revista como instância de difusão e legitimação ratificou em diferentes ocasiões o valor artístico do quinteto e de suas obras, já consagrados pelas audiências populares dos discos gravados e das músicas ao vivo difundidas pelos programas das emissoras de rádio e shows.

De modo a evidenciar o protagonismo que detinha na estrutura de distribuição das diferentes espécies de capitais em jogo no campo da produção musical popular no período, assim como acentuar o papel da importante rede de intermediários nordestinos que se constituíra na capital federal desde os anos 40, reforçando a importância das instâncias socialmente autorizadas a chancelar o reconhecimento artístico, Ruy Castro (2015) nos conta:

O cearense Humberto Teixeira chegara ao Rio em 1932, aos dezesseis anos, e nunca mais voltara ao Ceará. Era cunhado de outro cearense, o compositor Lauro Maia, autor da marchinha "Trem de Ferro" [...] gravada em 1944 pelo Quatro Ases e Um Coringa, e, em parceria com Humberto, do samba "Deus me Perdoe" [...], lançado por Cyro Monteiro em 1945. Na época de "Deus me Perdoe", Lauro levara a Humberto um acordeonista pernambucano chamado Luiz Gonzaga, que estava no Rio desde 1939 e tocava tangos, fados e fox-trotes nos bares da zona de prostituição, no Mangue. Ao sentir que estava marcando passo com aquele material estrangeiro, o rapaz procurara Lauro Maia para ajudá-lo a trabalhar com música do Nordeste. [...] Por sugestão de Humberto, trocaram aquela instrumentação [a original do baião: rabeca, viola e pandeiro] para acordeom, zabumba e triângulo e, em 1946, compuseram o primeiro exemplar [baião], intitulado simplesmente... Baião [...]. Gonzaga sentiu-se inseguro para gravá-lo, e o baião foi dado aos Quatro Ases e Um Coringa, que o levaram às

4 Para uma discussão sobre esta questão ver BARRETO, Mariana. João do Vale e a formação de um artista popular no Brasil, nos anos de 1950. Revista de Ciências Sociais. Vol. 46, No 2, Jul - Dez/2015. P. 201-224. 
paradas. Carmelia Alves aprendeu-o e o lançou em São Paulo e, em seguida, no Copacabana Palace. (p. 212-213).

A passagem sintetiza a sucessão de etapas que asseguraram o acesso à notoriedade, segundo as lógicas de reconhecimento que o caracterizavam. Torna possível vislumbrar a maneira como se distribuem artistas e obras nas hierarquias de prestígio, permite reconstituir a trajetória dos indivíduos como uma série de posições sucessivamente ocupadas por um mesmo agente ou por um grupo de agentes na estrutura de distribuição das diferentes espécies de capital em jogo no campo. Quatro Ases e Um Coringa, Carmelia Alves e o Copacabana Palace constituem, sem sombra de dúvidas, agentes, intermediários, e lugares que detém o monopólio do direito de entrada no campo da produção musical, do acesso à consagração e manutenção do reconhecimento e da distinção para os artistas e suas obras. Por outras palavras, asseguraram por mais de uma década o ingresso num campo da produção cultural brasileira.

Figura 3 - Partitura da Odeon da gravação de Eu vi um Leão (Lauro Maia, marcha/batuque) pelos Quatro Ases e Um Coringa em 1942.

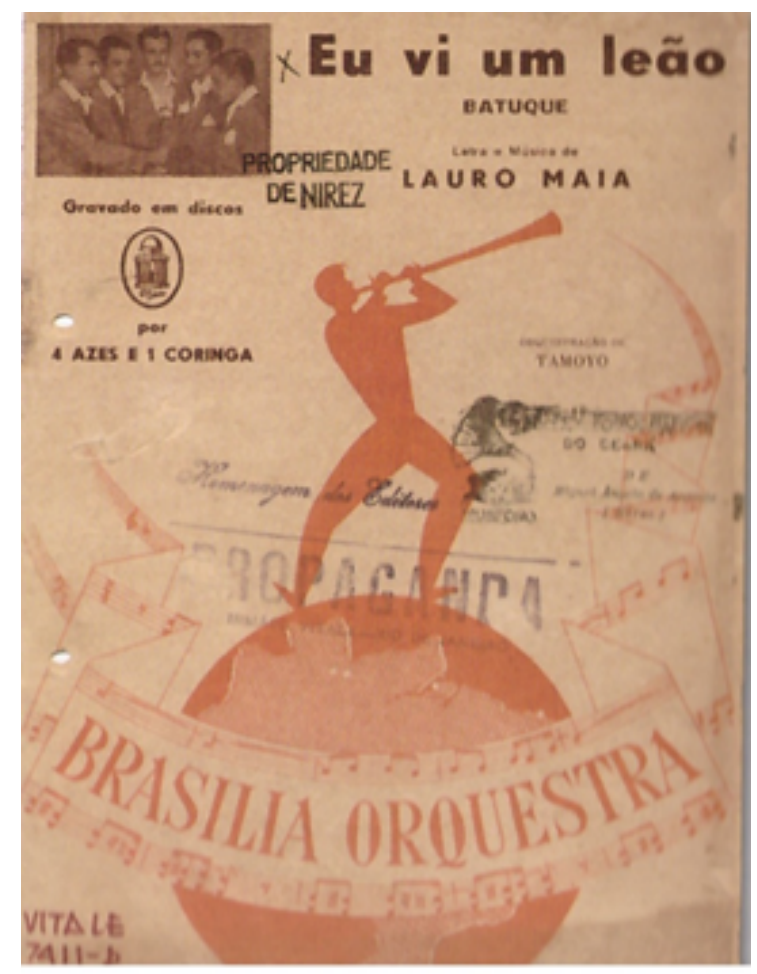

FONTE: AZEVEDO, Miguel A. de. Música popular no enfoque. In CHAVES, Gilmar; VELOSO, Patricia. e CAPELO, Peregrina. (Orgs.). Ah, Fortaleza. 2a Edição. Fortaleza: Terra da Luz, 2009. p. 150.

O veredito sobre o valor estético daquilo que produzia o grupo, expresso no sucesso comercial de suas obras, diz respeito ao papel de seleção desempenhado pelos agentes e instâncias acima referidos. No afluxo das alterações de seus monopólios de legitimação, ao longo da história, as classificações dos artistas e obras também sofrerão mutações. Dito de uma outra forma, os padrões de dependência que constituem a posição privilegiada destes grupos nas hierarquias culturais do período se alteram com frequência. São raros aqueles que perceberam este movimento e o acompanharam. De maneira restritiva, a justificativa mais comum, para explicar o fim dos grupos, é refratária da "acidentalidade" daquilo que se passa em termos das "mudanças naturais nos critérios de exigência do mercado".

\section{Os Vocalistas Tropicais, recomposições} pelo lugar de origem e o acesso à notoriedade.

Tanto Quatro Ases e Um Coringa quanto os Vocalistas Tropicais se formaram nos anos de 1940. Seus nomes denotam, em alguma medida, os arrimos identitários daquilo que produziam em termos materiais e simbólicos, isto é, o universo dos cassinos, das boates, das músicas regionais brasileiras, mas também americanas, centro e latino-americanas. A consolidação dos Vocalistas Tropicais e seu reconhecimento artístico estão intimamente relacionados a estas influências. Embora, o grupo tenha se formado em 1938 no Liceu do Ceará, na origem como Conjunto Liceal.

Apresentavam-se com frequência na Ceará Rádio Clube, precursora da TV Ceará, ambas sucursais dos Diários Associados ${ }^{5}$. Consagrados como acompanhantes da orquestra da emissora, excursionaram pelo Nordeste em direção ao Rio de Janeiro, onde apresentaram-se em estações de rádio e hotéis-cassinos. Chegaram a então capital 
federal em 1946, participaram dos programas ao vivo nas emissoras de rádio e cassinos, dois espaços privilegiados para o reconhecimento dos "novos talentos", quer estivessem prontos, ou precisassem ser "trabalhados", socialmente construídos. Para este tipo de empreendimento, as injunções identitárias vinculadas ao lugar de origem, precisaram se combinar a outras, tais como às influências dos estilos musicais preponderantes e aos capitais específicos em jogo, de modo a fazer emergir o irrefutável "talento" dos músicos. Uma vez conquistadas as primeiras posições de distinção, fizeram ainda acompanhamentos e solos em filmes nacionais, até, assim como os Quatro Ases e Um Coringa, assinarem contrato com a prestigiada Odeon, companhia que produziu mais da metade dos cinquenta discos lançados pelo grupo entre os anos de 1946 e 1958 (AZEVEDO, 2004, 2009).

Figura 4 - Vocalistas Tropicais.

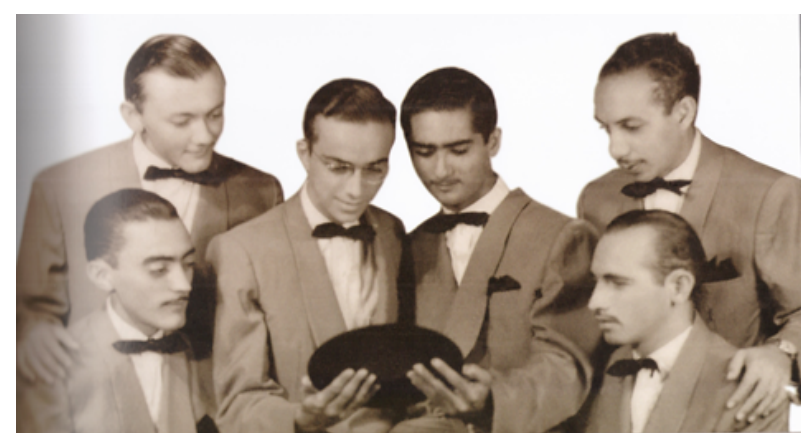

FONTE: AZEVEDO, Miguel A. de. Música popular no enfoque. In CHAVES, Gilmar; VELOSO, Patricia. e CAPELO, Peregrina. Ah, Fortaleza. 2a Edição. Fortaleza: Terra da Luz, 2009. p. 147.

Com certa instabilidade em sua formação original, após várias reconfigurações, os Vocalistas Tropicais são reconhecidos pelas execuções de sambas, marchas e balanceios interpretados pelos cearenses: Nilo Xavier Mota, Danúbio Barbosa Lima, Raimundo Evandro Jataí de Souza, Arlindo Borges e Artur de Oliveira. Antes disso, da formação do Conjunto Liceal restaram poucos integrantes, dentre eles Danúbio Barbosa. Desde os tempos do cast da Ceará Rádio Clube, e suas versões para os sambas e canções românticas que faziam a audiência dos programas ao vivo da emissora, expunham-se os efeitos deletérios das alterações na composição do grupo. Na verdade, os Vocalistas Tropicais parece ter nascido da fusão de dois grupos criados no Liceu do Ceará: o Conjunto Liceal e o Trio NAP, composto por Nilo Xavier, José Arthur de Carvalho e José Eduardo Pamplona. O Trio NAP, mais Danúbio Barbosa e Olavo Cordeiro, formou a primeira versão dos Vocalistas.

A estreia dos vocalistas e instrumentistas nesta versão inicial aconteceu num dos programas de calouros da Ceará Rádio Clube com três vocalistas acompanhados por um tamborim, um violão e um cavaquinho. O repertório dos músicos, neste momento, era profundamente influenciado por referências nacionais como o Bando da Lua e Anjos do Inferno, e pelas composições dos cearenses Lauro Maia, José Arthur Carvalho e José Jatahy.

Os vínculos estabelecidos na Ceará Rádio Clube ofereceram aos artistas condições materiais de criação e, consequente, difusão de suas obras. Rapidamente excursionaram pelo interior do Ceará, foram levados para outras cidades nordestinas, para o norte do país, até gravarem seu primeiro disco, apenas um ano após sua primeira aparição pública em 1941. Quando foram ao Rio de Janeiro, em 1945, já haviam assinado um contrato de trabalho com a Rádio Tupi, a emissora carioca que primeiro os acolheu, abrindo-lhes as portas para o acesso à rede de intermediários cearenses estabelecidos no campo da produção musical radiofônica na cidade. A

5 Para uma discussão sobre a importância dos Diários Associados para a processo de modernização cultural do Ceará ver BARRETO, Mariana Tv Ceará: processo de modernização da cultural local. Dissertação de mestrado. Universidade Estadual de Campinas - UNICAMP, 2009. http://repositorio.unicamp.br/jspui/handle/REPOSIP/281863. Problemática sintetizada em BARRETO, Mariana. Tv Ceará: processo de modernização da cultural local. Revista Pós Ciências Sociais. Vol. 5, No 9/10, 2008. http://www.periodicoseletronicos.ufma.br/index.php/rpcsoc/article/view/776 
partir daí, incrementaram-se a diversificação das novas oportunidades de trabalho, os artistas se dividiram entre as apresentações regulares nos programas da estação de rádio, entre as turnês dentro e fora do país, entre as gravações de discos, participações em filmes e execuções de trilhas sonoras para as companhias cinematográficas (LIMA, 2006).

As apresentações rotineiras na Rádio Tupi e a realização do musical "Balanceio", sob a direção do maestro e compositor cearense Paurillo Barroso no Cassino Balneário Atlântico franquearam o reconhecimento do talento artístico do grupo e fomentaram a assinatura do primeiro contrato com a Odeon em 1946. Da mesma forma, esta primeira gravação trouxe composições de dois outros cearenses: Paulo Sucupira com o fox Papai, Mamãe, Você e Eu e Lauro Maia e seu balanceio Tão Fácil, Tão Bom. A participação em filmes já havia acontecido desde a passagem de Orson Welles pelo Ceará para as filmagens de "It's all true", e intensificou-se após a realização de "Caídos do Céu" (1946), onde os Vocalistas atuaram ao lado de Dercy Gonçalves e Adoniran Barbosa interpretando Tão Fácil, Tão Bom, e "Carnaval no Fogo" (1949) produzido pela Atlântida onde atuaram executando a marcha Daqui Não Saio (CRAVO ALBIN, 2018; AZEVEDO, 2009).

Dentro da Odeon, os Vocalistas se destacaram pelas interpretações, rapidamente transformadas em sucessos nacionais, de marchinhas carnavalescas como Daqui Não Saio (1949), Jacarepaguá (1949), Tomara Que Chova (1950), compostas por Paquito, Romeu Gentil e Marino Pinto. Pela Copacabana Discos gravaram Turma do Funil (1956), de Mirabeau, Milton de Oliveira e Urgel de Castro, sucessos populares replicados quando lançaram, pela gravadora Continental, o samba de Zé Keti, A Voz do Morro (1955). O s grupos musicais ocuparam lugar privilegiado no campo da produção musical popular brasileira até o início dos anos 60, quando alteram-se os sentidos e significados do popular, dos artistas e de suas composições, transmutando a morfologia do mercado de música popular como um todo. A inteligibilidade das alterações operadas, para quem foi parte deste processo, se dá por outro caminho. Para o vocalista Nilo Mota (AZEVEDO, 1971), por exemplo,

[...] [os Vocalistas Tropicais] não se dissolveu, o conjunto apenas parou de trabalhar. Cansou, saturou. Entraram novos conjuntos. Uma turma com mais saúde, com mais vitalidade, com um repertório diferente. Na época, chamava-se "a invasão dos cabeludos". Esses meninos começaram a trabalhar por qualquer preço, de graça ou pagando, e isso mexeu muito com os brilhos dos [outros] profissionais [...], porque inclusive os diretores de emissoras, os donos de programas já davam mais facilidade pra esses meninos por várias razões, e a principal é que não dava despesa pra eles. E inclusive o público jovem aderia, aceitava muito esses garotos, deixando os mais antigos, assim, num segundo plano, a ponto da maioria abandonar, como nós fizemos.

Os Vocalistas Tropicais seguiram trabalhando até a década de 70, gravando alguns discos, retomando gêneros e ritmos musicais com os quais haviam erigido uma carreira de sucesso dentro e fora do país. A forma como a cultura popular será reinterpretada a partir do desenvolvimento e consolidação de uma indústria cultural no Brasil, nos anos 60 e 70, estará assentada sob uma hegemonia que aperfeiçoa, desenvolve, diversifica e difunde os meios de comunicação, buscando integrar todo o país, transformando o conceito de "popular" e seu sentido no campo da cultura. Fortemente administrada pelo Estado, submetida a um processo de racionalização ímpar, a esfera

6 Segundo os Vocalistas, o "balanceio" foi um ritmo criado por Danúbio Barbosa Lima, quando das primeiras interpretações realizadas pelos Vocalistas Tropicais. Ganhou reconhecimento a partir das composições de Lauro Maia, ainda que o primeiro balanceio, “Tiririca”, tenha sido composto por Aleardo Freitas, e gravado pelos Vocalistas Tropicais. Explicam ainda que o balanceio "consiste na mistura das marchinhas cariocas com os ritmos tipicamente nordestinos". (Negrito nosso). (AZEVEDO, 1971). 
da cultura refletia a política de planejamento das ações governamentais em diferentes âmbitos administrativos, cujo propósito era dar uma nova orientação ao modelo de desenvolvimento da sociedade brasileira.

Um mercado cultural desenvolvido em dimensões nacionais, integrando as diferenças regionais fazia parte deste modelo, que ganhou força a partir de 1964 com o reforço, por parte do Estado autoritário, do uso da cultura como meio de integração do espaço público, parte da política de Segurança Nacional. Neste período, expandem e consolidam-se os grandes conglomerados da comunicação e do entretenimento no mercado brasileiro, crescem os números de produtos consumidos em diversas áreas eo próprio mercado brasileiro tem sua importância internacional impulsionada por uma articulação bem urdida entre Estado e companhias multinacionais, seus dois maiores investidores (ORTIZ, 1988).

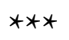

Este artigo introdutório não poderia apresentar considerações conclusivas. Como advertimos, ele é produto de achados interpretativos fruto das primeiras imersões em um pequeno número de dados empíricos coletados. Seu objetivo é apresentar, dispor para debate, elementos significativos da formação de nossa cultura nacional, de parte de nossa formação societária, muitas vezes rechaçada e acentuar a importância dos trabalhos desenvolvidos nas regiões do país, muitas vezes tomadas como periféricas, numa outra chave compreensiva. Primeiro, abrindo mão de enfoques comparativos desiguais do tipo: centros com maiores graus de autonomia e periferias marcadas pela heteronomia. Acreditamos que a comparação nestes termos mostra-se improdutiva, pois faz perder de vista características importantes dos padrões de dependência que marcaram as formações periféricas, constitutivos de sua heteronomia. Além disso, tais padrões, quer tenham se formado em referência a uma demanda de classe, exigência política, ou em consonância com uma autoridade cultural, não se limitam aos trânsitos locais e nacionais ${ }^{7}$. As estratégias de atuação entre campos nacionais dominantes e dominados, têm no espaço internacional um lugar privilegiado para a subversão das dominações, como já mostrou Sapiro $\left(2013\right.$, p.78) ${ }^{8}$. Para as formações regionais, as coisas não se passam de modo tão distinto, isto é, elas não se conformam aos seus espaços regionais e nacionais; trânsitos de empréstimos e intercâmbios entre produtos das indústrias culturais se realizam nos espaços transnacionais, onde também participam. É justamente um estudo dedicado à trajetória destes grupos musicais originalmente "periféricos" que pode romper com a crença de que só há o que dizer sobre a heteronomia de um campo musical se comparada à autonomia de outro, cujos padrões de dependência há muito deixaram de existir.

Uma última palavra sobre as homologias entre as trajetórias dos artistas consagrados e a estrutura do campo de produção da música popular brasileira. Parece certo que os itinerários dos conjuntos "regionais" e a atribuição do valor de suas obras (expressivas da cultura nacionalpopular) se fazem numa mistura sincrética. Seria impossível descrevê-las, encerrando-as em rígidas fronteiras regionais, nacionais, internacionais ou transnacionais, como ratificamos. As carreiras e obras produzidas aqui parecem mais heterogêneas do que nos fazem crer as formações das identidades nacionais, quando examinadas a partir de suas representações nas músicas populares. ${ }^{9} \quad$ Elas se fazem a partir dos papéis

7 Para uma recente e aprofundada discussão nestes termos ver MICELI, 2018.

8 Em síntese, a autora mostra que quanto mais os campos nacionais ocupam posições dominadas no espaço internacional, mais seus hegemônicos se voltarão para os espaços internacionais, capazes de impor modelos estrangeiros em seus países. Por outro lado, quanto mais os campos nacionais ocupam posições dominantes no espaço internacional, mais seus hegemônicos se concentrarão sobre a acumulação de capital simbólico no âmbito nacional, garantindo sua visibilidade internacional.

9 O que não significa dizer que as trocas realizadas sejam simétricas. 
específicos que desempenham as gravadoras de discos, os produtores musicais, os produtores de shows e turnês, as redes internacionais, formais e informais, de profissionais da música, e as políticas públicas de apoio a circulação internacional da música popular brasileira desde tempos bem remotos.

Por fim, seria pouco provável a realização disso sem a configuração das instâncias de difusão e legitimação no período, enredando um grupo significativo de compositores, intérpretes, radialistas, diretores de estações de rádio, apresentadores de programas de auditório cearenses e, por isso, favorecendo aproximações e o consequente desenvolvimento de trabalhos conjuntos. Gravadoras de discos, emissoras de rádio, cassinos e boates representavam a excelência dos produtores musicais $\mathrm{e}$ as vias de acesso mais legítimas às posições mais elevadas dentro do campo de reprodução da música popular brasileira no período. A circulação internacional destes grupos, em turnês pela América Latina ${ }^{10}$, atesta a força desta estrutura, ao mesmo tempo em que fomentava as diferenças de notoriedade para artistas e obras. Nessa hierarquia, em termos de gêneros musicais, são representativos da música popular brasileira sambas e marchas carnavalescas, dois dos gêneros musicais responsáveis pelas projeções extraterritoriais de nossos Bando Cearense e Conjunto Liceal, abrindo-lhes acesso à notoriedade e ao reconhecimento artísticos, crismando-os pelas designações de Quatro Ases e Um Coringa e Vocalistas Tropicais, respectivamente.

\section{Referências}

AZEVEDO, Miguel A. de. No tempo dos vocalistas. Jornal Diário do Nordeste, 08/05/2004. Disponível em http://diariodonordeste. verdesmares.com.br/editorias/verso/no-tempodos-vocalistas-1.625110. Acesso em 26/02/2018.
Música popular no enfoque. In CHAVES, Gilmar; VELOSO, Patricia. e CAPELO, Peregrina. (Orgs.). Ah, Fortaleza. 2a Edição. Fortaleza: Terra da Luz, 2009.p. 147 - 153.

BARRETO, Mariana. Tv Ceará: processo de modernização da cultural local. Revista Pós Ciências Sociais. Vol. 5, No 9/10, 2008. Disponível em http://www.periodicoseletronicos.ufma.br/ index.php/rpcsoc/article/view/776.

Tv Ceará: processo de modernização da cultural local. Dissertação de mestrado. Universidade Estadual de Campinas - UNICAMP, 2009. Disponível em http://repositorio.unicamp. br/jspui/handle/REPOSIP/281863.

. João do Vale e a formação de um artista popular no Brasil, nos anos de 1950. Revista de Ciências Sociais. Vol. 46, No 2, Jul - Dez/2015. p. 201-224.

. O artista popular e o contrato: lógicas divergentes na produção musical. Revista Ciências Sociais Unisinos, Vol. 2, No 52, Maio-Agosto/2016. p. 253-262.

. Por uma sociologia do artista popular.

Revista Política \& Sociedade. V. 17, N. 38, maioagosto de 2018. (No prelo).

CASTRO, Ruy. A Noite do Meu Bem. A história e as histórias do samba-canção. São Paulo: Companhia das Letras, 2015.

CRAVO ALBIN. Quatro Ases e Um Coringa [verbete]. Dicionário Cravo Albin da Música Popular Brasileira. Disponível em http:// dicionariompb.com.br/quatro-ases-e-umcoringa. Acesso em 26/02/2018.

\section{Vocalistas Tropicais [verbete].}

Dicionário Cravo Albin da Música Popular 
Brasileira. Disponível em http://dicionariompb. com.br/vocalistas-tropicais. 26/02/2018.

Acesso

em

LIMA, Danúbio B. A Saga dos Vocalistas Tropicais. Fortaleza:Casa da Memória Equatorial,2006.

LIZÉ, Wenceslas; NAUDIER, Delphine e ROUEFF, Olivier (Orgs.). Intermédiaires $d u$ Travail Artistique. À la frontière de l'art et du commerce. Paris: Ministère de la Culture et de la Communication et Secrétariat des études, de la prospective et des statistiques (DEPS), 2011.

LIZÉ, Wenceslas. Trajectoires de consécration et transformations des champs artistiques. In Sociologie et Sociétés, Vol. 47, N. 2, 2015.

MICELI, Sérgio. Sonhos da Periferia. Inteligência argentina e mecenato privado. São Paulo: Todavia, 2018.

ORTIZ, Renato. A Moderna Tradição Brasileira. São Paulo: Brasiliense, 1988.

Revista do Rádio, Ano III, No 24, Fevereiro de 1950.

RIVRON, Vassili. Le reclassement de la musique populaire brésilienne - Trajectoires de producteurs radiophonique et construction d'un patrimoine national (1936 - 1970). Regards Sociologiques (Dossier "Les champs artistique"). No 33/34, Juin 2007.

SAPIRO, Gisle. Le champ est-il national? La théorie de la différenciation social au prisme de l'histoire globale. In Actes de la Recherche en Sciences Sociales, Théorie du Champ, No 200, Décembre 2013. P.71 a 85.

Áudios:

AZEVEDO, Miguel.A.de. Entrevista com Nilo Xavier da Mota. Fortaleza, Março de 1971.
Filmes:

Caídos do Céu. Dir: Luiz Barros, Brasil, 1946.

Carnaval no Fogo. Dir.: Watson Macêdo, Brasil, 1949.

It's all true. Dir.: Orson Welles, EUA, 1942.

\section{(n)}

